\title{
Construction of an electrochemical sensing platform based on platinum nanoparticles supported on carbon for tetracycline determination
}

\author{
Ricardo T. Kushikawa ${ }^{a}$, Marcelo R. Silva ${ }^{\mathrm{b}}$, Antonio C.D. Angelo ${ }^{\mathrm{b}}$, Marcos F.S. Teixeira ${ }^{\mathrm{c}, *}$ \\ a São Carlos Institute of Chemistry, University of São Paulo (USP), São Carlos, SP, Brazil \\ ${ }^{\mathrm{b}}$ Faculty of Science, São Paulo State University (UNESP), Bauru, SP, Brazil \\ ${ }^{c}$ Faculty of Science and Technology, São Paulo State University (UNESP), Presidente Prudente, SP, Brazil
}

\section{A R T I C L E I N F O}

\section{Article history:}

Received 17 September 2015

Received in revised form

27 December 2015

Accepted 5 January 2016

Available online 8 January 2016

\section{Keywords:}

Electrochemical sensor

Platinum nanoparticles

Voltammetric determination

\begin{abstract}
A B S T R A C T
In this paper, we report the construction of an electrochemical sensing platform based on platinum nanoparticles supported on carbon (PtNPs/C) for the determination of the antibiotic tetracycline (TTC). Initially, the PtNPs/C was synthesized and characterized by powder X-ray diffraction spectroscopy and transmission electron microscopy. The effect of experimental parameters on the electrochemical behavior of the PtNPs/C coated glassy carbon electrode (PtNPs/C/GCE), including the amount of PtNPs and electroactive area, scan rate and $\mathrm{pH}$, were evaluated. The electrooxidation of TTC on the PtNPs/C/GCE was investigated by cyclic voltammetry and differential pulse voltammetry, with the determination of TTC electrooxidation mechanism. Under optimum experimental conditions, the linear calibration range, detection limit, quantification and sensitivity of the PtNPs/C/GCE were $9.99-44.01 \mu \mathrm{mol} \mathrm{L}^{-1}$, $4.28 \mu \mathrm{mol} \mathrm{L}^{-1}, 14.3 \mu \mathrm{mol} \mathrm{L}^{-1}$ and $3.32 \mu \mathrm{AL} \mu \mathrm{mol}^{-1} \mathrm{~cm}^{-2}$, respectively. Finally, the proposed electrochemical sensing platform was successfully applied to determine low TTC concentrations in urine samples, suggesting its great applicability in clinical analysis and quality control.
\end{abstract}

(c) 2016 Elsevier B.V. All rights reserved.

\section{Introduction}

Tetracyclines (TTC) are a group of antibiotics that are useful in the treatment of many bacterial infections and widely used in animal breeding industry as growth agents [1]. The excessive use of antibiotics leads to bacterial resistance [2], and their widespread presence in soil, waste water and animal foods. The presence of the TTC in the environment can lead to suppression of microorganism activities and its presence in water treated with chlorine oxidants and chlorine dioxide can generate potentially carcinogenic chlorinated products [3]. Therefore, several methods have been developed to detect and quantify the TTC, the most common being capillary electrophoresis [4-6], high performance liquid chromatography $[7,8]$ liquid chromatography $[9,10]$ spectroscopic techniques [11,12] and electrochemoluminescence $[13,14]$. However, many of these techniques are time consuming, require numerous analytical steps and high operational cost and are also difficult to be used in situ. Under these circumstances,

\footnotetext{
* Corresponding author. Fax: +55 1832215682.

E-mail address: funcao@fct.unesp.br (M.F.S. Teixeira).
}

electrochemical sensors show interesting characteristics, such as simplicity, fast response and they can be applied for the determination of analytes directly in the sample, without any pretreatment or chemical separation [15]. For this purpose, an electrochemical sensor based on a bare graphite-polyurethane composite electrode was evaluated for the determination of tetracycline in human urine [16] and natural water samples [17].

Among the materials applied in the construction of electrochemical sensors, nanomaterials have attracted attention due to their electronic, optical, and catalytic properties [18-20]. Nanoparticle-modified electrodes present several advantages over the macroelectrodes in electroanalysis, such as catalysis, enhancement of mass transport, high effective surface area and control over electrode microenvironment [21]. Platinum is widely used in industry as catalyst and despite its high cost, it presents high stability and electrical conductivity, which makes it attractive for the development of sensors [22,23]. Most electrochemical sensing platforms containing nanoparticles combined with other materials for tetracycline detection are based on gold nanoparticles [24-27].

The goal of the present study was to develop and optimize an electrochemical sensing platform using platinum nanoparticles 
supported on carbon for tetracycline determination. The method was validated and tested by analyzing urine samples.

\section{Experimental}

\subsection{Apparatus}

The electrochemical measurements were made using a potentiostat/galvanostat microAutolab Type III (Eco Chimie-Netherlands) in a thermostated electrochemical cell $(T=298 \mathrm{~K})$ with three electrodes, being the platinum wire $(\mathrm{Pt})$ as auxiliary electrode, saturated calomel electrode (SCE) as reference electrode and (uncoated or coated) glassy carbon electrode as working electrode (geometric area $=0.071 \mathrm{~cm}^{2}$ ). For $\mathrm{pH}$ adjustments, a Metrohm $691 \mathrm{pH}$ meter (Methohm Autolab-Switzerland) was used.

\subsection{Reagents and solutions}

All solutions were prepared using deionized water and all chemicals were of analytical grade (Sigma-Aldrich analytical reagents) and used without further purification. A solution of $0.01 \mathrm{~mol} \mathrm{~L}^{-1} \mathrm{~K}_{3}\left[\mathrm{Fe}(\mathrm{CN})_{6}\right]$ containing $0.5 \mathrm{~mol} \mathrm{~L}^{-1} \mathrm{KCl}$ was used to determine effective area of the coated electrode. The universal buffer solution was prepared by the dissolution of $\mathrm{Na}_{2} \mathrm{~B}_{4} \mathrm{O}_{7}$ $\left(5.7 \mathrm{mmol} \mathrm{L}^{-1}\right), \mathrm{Na}_{2} \mathrm{HPO}_{4}\left(0.02 \mathrm{~mol} \mathrm{~L}^{-1}\right), \mathrm{C}_{6} \mathrm{H}_{8} \mathrm{O}_{7}\left(0.01 \mathrm{~mol} \mathrm{~L}^{-1}\right)$ and $\mathrm{KCl}\left(0.5 \mathrm{~mol} \mathrm{~L}^{-1}\right)$ in $0.5 \mathrm{~L}$ deionized water. The phosphate buffer solution $\left(0.1 \mathrm{~mol} \mathrm{~L}^{-1}\right)$ was prepared by mixing $\mathrm{H}_{3} \mathrm{PO}_{4}$ and $\mathrm{NaH}_{2} \mathrm{PO}_{4}$ also solubilized in deionized water. All $\mathrm{pH}$ adjustments were made by adding $\mathrm{HCl}$ and/or $\mathrm{NaOH}$, both $6.0 \mathrm{~mol} \mathrm{~L}^{-1}$. Tetracycline standard solution $\left(0.01 \mathrm{~mol} \mathrm{~L}^{-1}\right)$ was prepared by dissolution of an appropriate amount of tetracycline hydrochloride in phosphate buffer.

\subsection{Supported platinum nanoparticles preparation and characterization}

The supported platinum nanoparticles (PtNPs/C) were prepared in the proportion of 20:80 (w/w) metal:carbon support, based on previously reports [28-30]. Firstly, $60 \mathrm{~mL}$ ethylene glycol and $400 \mathrm{mg}$ of finely powdered carbon (Vulcan XC-72 ${ }^{\circledR}$ ) were mixed in a beaker, which was treated in an ultrasonic bath for $2 \mathrm{~h}$ in an inert nitrogen atmosphere, to disperse the support in the solvent. Next, a weighed quantity of $\mathrm{H}_{2} \mathrm{PtCl}_{6} \cdot 6 \mathrm{H}_{2} \mathrm{O}$ was dissolved in the deaerated solvent and kept at $140^{\circ} \mathrm{C}$ refluxing for $4 \mathrm{~h}$. The final product, a black powder, was washed five times with acetone and then five times with deionized water. The powder was then dried in an oven at $80^{\circ} \mathrm{C}$ for $24 \mathrm{~h}$. The PtNPs/C synthesized was characterized by powder X-ray diffraction spectroscopy (pXRD), with a Rigaku RINT 2000 (Rigaku-Japan) diffractometer equipped with a $\mathrm{Cu}-\mathrm{K} \alpha_{1}$ radiation source. The spectra were recorded as a mean of 3 scans, at a rate of $1^{\circ} \mathrm{min}^{-1}$, from $2 \theta=20^{\circ}-80^{\circ}$. The morphology, distribution and size of the material were observed with a JEOL transmission electron microscope (TEM) model JEM-1200 EX II (XRD: 3.927 exp.; 3.923 PCPDFWin.; mean particle diameter (nm): 7.4 by XRD; 7.6 by TEM).

\subsection{Preparation of electrochemical sensing platform}

The bare glassy carbon electrode was polished with alumina $(<50 \mathrm{~nm})$ and diamond power suspension. After polishing, the electrode was immersed in ethanol absolute and abundantly washed with deionized water. Finally, the polished electrode was submitted to potential cycles at scan rate $25 \mathrm{mV} \mathrm{s}^{-1}$ in a potential range from -1.0 to $+1.0 \mathrm{~V} v s$. SCE in $0.1 \mathrm{~mol} \mathrm{~L}^{-1} \mathrm{H}_{2} \mathrm{SO}_{4}$ solution until to obtain a stable voltammetric profile $[31,32]$.

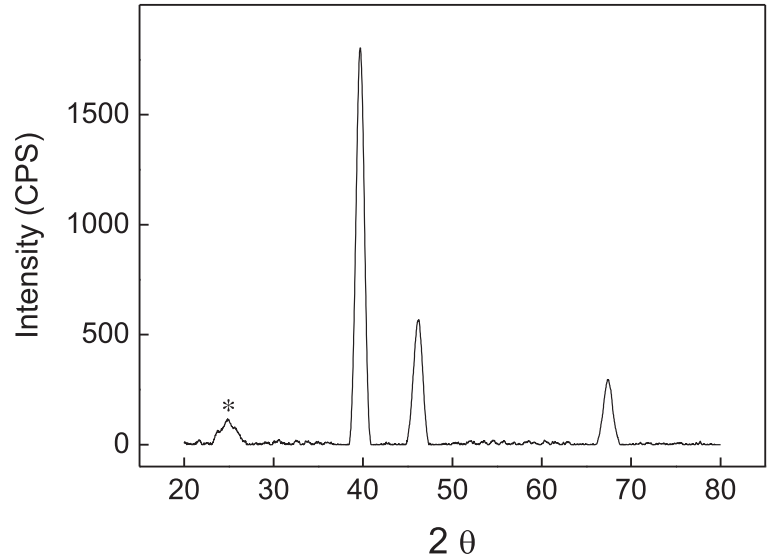

Fig. 1. Powder XRD patterns for PtNPs/C.

The electrode surface was coated with multiple additions of $10 \mu \mathrm{L}$ of $0.1 \% \mathrm{w} / \mathrm{v}$ PtNPs/C in DMF. The additions were realized following an interval of approximately $3 \mathrm{~h}$ after complete evaporation of the solvent. After each coating, the effective electroactive area was determined by chronoamperometry.

\subsection{Electrochemical performance of the PtNPs/C/GCE}

The electrochemical behavior of the PtNPs/C/GCE was investigated by cyclic voltammetry and chronoamperometry in $0.5 \mathrm{~mol} \mathrm{~L}^{-1} \mathrm{KCl}$ containing $0.01 \mathrm{~mol} \mathrm{~L}^{-1} \mathrm{~K}_{3}\left[\mathrm{Fe}(\mathrm{CN})_{6}\right]$. The voltammetric determination of TTC at the PtNPs/C/GCE was investigated in $0.1 \mathrm{~mol} \mathrm{~L}^{-1}$ phosphate buffer solution ( $\mathrm{pH}$ 3.0) using the cyclic voltammetry (CV) and differential pulse voltammetry (DPV).

\subsection{Application of electrochemical sensing platform in urine samples}

The electroanalytical application of the PtNPs/C/GCE was performed using human urine samples without treatment [33]. The human urine consists primarily of water, urea, creatinine, uric acid, and trace amounts of enzymes, carbohydrates, hormones, fatty acids, pigments, mucins, and inorganic ions such as sodium, potassium, chloride, magnesium, calcium, ammonium, sulfates and phosphates.

The urine samples were purposely contaminated with $4.00 \times 10^{-3} \mathrm{~mol} \mathrm{~L}^{-1}$ TTC and adjusted to $\mathrm{pH} 3.0$. The analysis were conducted using cyclic voltammetry between +0.6 to $+1.2 \mathrm{~V}$ (vs. SCE) at $25 \mathrm{mV} \mathrm{s}^{-1}$ in $0.1 \mathrm{~mol} \mathrm{~L}^{-1}$ phosphate buffer solution ( $\mathrm{pH}$ 3.0). After recording a CV scan in the absence of TTC, one aliquot of the urine sample was added to the electrochemical cell, obtaining a final concentration equivalent to $19.9 \times 10^{-6} \mathrm{~mol} \mathrm{~L}^{-1}$ TTC. Successive additions of a TTC standards solution were realized.

\section{Results and discussion}

\subsection{Nanoparticle characterization}

The diffraction peaks (Fig. 1) were compared with literature data (PCPDFWin Version 2.4, JCODS-ICDD) and the crystallographic entry for Pt (PDF \#04-0802) led to the identification of the metallic structure as belonging to the FCC cubic system with Fm3m (225) space group. The sample showed an intense peak at about $2 \theta=40^{\circ}$, representing the diffraction from plane $(100)$. The peak of low intensity $\left(2 \theta=25^{\circ}\right)$ corresponds to carbon support, which is typically seen in materials supported on carbon [28]. 


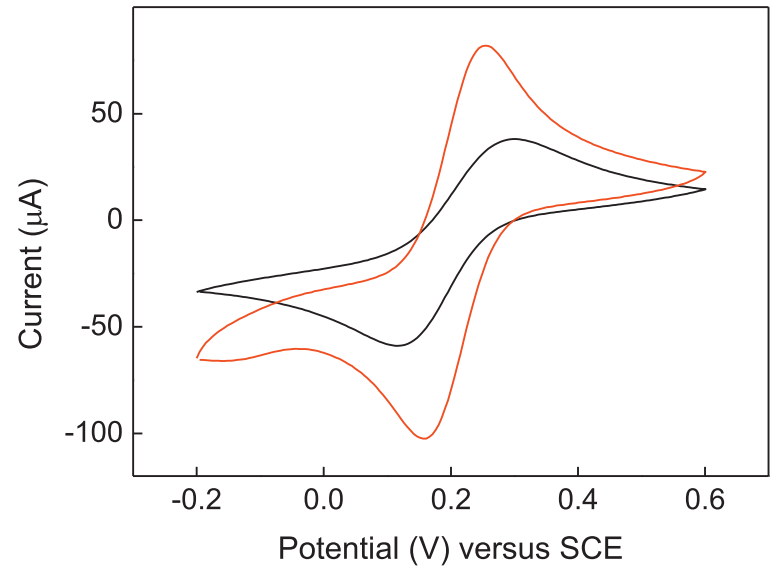

Fig. 2. Cyclic voltammograms recorded in a solution of $0.5 \mathrm{~mol} \mathrm{~L}^{-1} \mathrm{KCl}$ containing $0.01 \mathrm{~mol} \mathrm{~L}^{-1} \mathrm{~K}_{3}\left[\mathrm{Fe}(\mathrm{CN})_{6}\right]$ from $-0.2 \mathrm{~V}$ to $0.6 \mathrm{~V} v \mathrm{~s}$. SCE at $25 \mathrm{mV} \mathrm{s}^{-1}$ for the uncoated (black curve) and coated electrode with $10 \mu \mathrm{L}$ of $0.1 \% \mathrm{w} / \mathrm{v}$ PtNPs/C suspension (red curve). (For interpretation of the references to color in this figure legend, the reader is referred to the web version of this article.)

An estimate of the mean size of the metal particles dispersed in the larger particles of carbon was obtained by means of the Scherrer formula. The mean particle diameter was around $7.4 \pm 0.2 \mathrm{~nm}$. The transmission electron microscope images (Supplementary material-SM1) show that the metal particles was highly dispersed and distributed homogeneously over the carbon support. Comparing the particle sizes estimated by TEM and XRD, it was found that the two sets of results are remarkably similar.

\subsection{Performance of the electrochemical sensing platform}

Firstly, cyclic voltammograms for the bare and the PtNPs/C/GCE were obtained in a solution of $0.5 \mathrm{~mol} \mathrm{~L}^{-1} \mathrm{KCl}$ containing $0.01 \mathrm{~mol} \mathrm{~L}^{-1} \mathrm{~K}_{3}\left[\mathrm{Fe}(\mathrm{CN})_{6}\right]$, applying potentials between -0.2 to $0.6 \mathrm{~V}$ $v s$. SCE at scan rate of $25 \mathrm{mV} \mathrm{s}^{-1}$. As presented in Fig. 2, the modification of the electrode surface by PtNPs/C lead to an increase in both anodic and cathodic peak current, assigned to the activity of the nanoparticles.

Thus, the effect of the amount of material (1-6 mg of PtNPs/C) deposited on the GCE surface was determined by comparing the effective electroactive area using chronoamperometry at different applied potentials in $\mathrm{K}_{3}\left[\mathrm{Fe}(\mathrm{CN})_{6}\right]$ solution, the results obtained being shown in Fig. 3.

Cottrell's equation [34] was used to analyze the data obtained by chronoamperometry:

$I=\frac{n F A C_{0} \sqrt{D_{0}}}{\sqrt{\pi t}}$

where $A$ is the effective electroactive area of the electrode $\left(\mathrm{cm}^{2}\right), I$ is the current value $(\mathrm{A}), n$ is the number of electrons (assuming $\approx 1), F$ is the Faraday constant $\left(96,485 \mathrm{C} / \mathrm{mol} \mathrm{e}^{-}\right.$), $C_{0}$ initial concentration of the reducible hexacyanoferrate(III) $\left(\mathrm{mol} \mathrm{cm}{ }^{-3}\right), D_{\mathrm{o}}$ diffusion coefficient of the hexacyanoferrate(III) $\left(7.70 \times 10^{-6} \mathrm{~cm}^{2} \mathrm{~s}^{-1}\right)[35,36]$ and $t$ is the time (s). The slope values obtained via the chronoamperograms (current vs. $1 / \sqrt{t}$ ) are exposed in Table 1 , as well as the effective electroactive areas, calculated from of Eq. (1) for the uncoated and coated electrode.

There is a continuous increase in the effective electroactive area up to $5 \mathrm{mg}$ PtNPs/C ( $50 \mu \mathrm{L}$ suspension), by a factor of ten, from $0.0357 \mathrm{~cm}^{2}$ for the bare GCE to $0.3936 \mathrm{~cm}^{2}$ for the PtNPs/C/GCE followed by a decrease for the GCE coated with $6 \mathrm{mg}$ PtNPs/C $(60 \mu \mathrm{L}$ suspension), probably due to a loss of contact between particles in a thicker layer $[37,38]$. Thus, the subsequent experiments were performed using the coverage with $50 \mu \mathrm{L}$ of $0.1 \% \mathrm{w} / \mathrm{v}$ PtNPs/C.

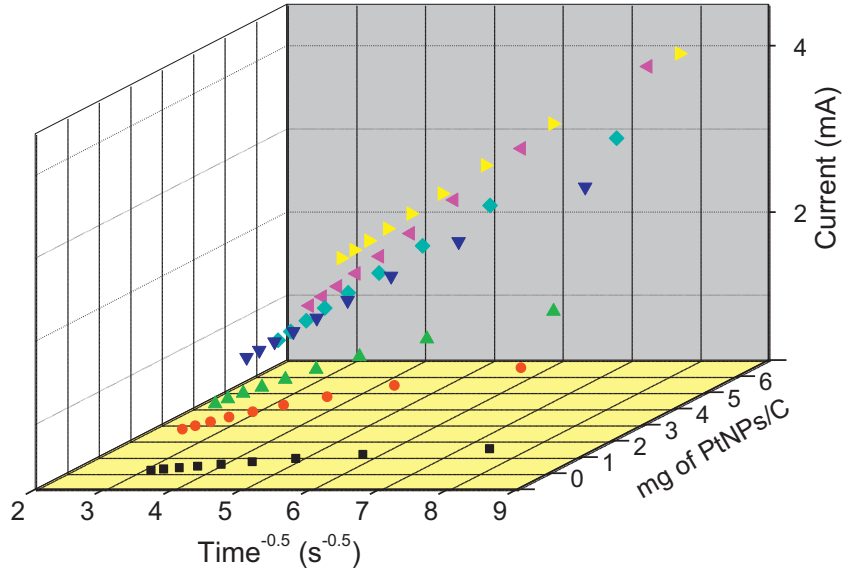

Fig. 3. Cottrells plot obtained in $0.5 \mathrm{~mol} \mathrm{~L}^{-1} \mathrm{KCl}$ containing $0.01 \mathrm{~mol} \mathrm{~L}^{-1} \mathrm{~K}_{3}\left[\mathrm{Fe}(\mathrm{CN})_{6}\right.$ from $-0.1 \mathrm{~V}$ to $+0.5 \mathrm{~V} v \mathrm{~s}$. SCE with duration of $1 \mathrm{~s}$ and time interval lower than $0.1 \mathrm{~s}$ for the (ם) unmodified and modified electrode with $\left(\boldsymbol{\square}_{)} 1 \mathrm{mg},(\Delta) 2 \mathrm{mg},(\nabla) 3 \mathrm{mg}\right.$, $(\diamond) 4 \mathrm{mg},(\varangle) 5 \mathrm{mg}$ and $($ ) $6 \mathrm{mg}$ of PtNPs/C. (For interpretation of the references to color in this figure legend, the reader is referred to the web version of this article.)

Table 1

Values of slope and electroactive area calculated using the Cottrell equation for the bare GCE and GCE coated with different amounts of PtNPs/C.

\begin{tabular}{lll}
\hline Electrode & Slope $\left(\mathrm{mAs}^{1 / 2}\right)$ & Electroactive area $\left(\mathrm{cm}^{2}\right)$ \\
\hline Uncoated & $5.39 \times 10^{-5}$ & 0.036 \\
$1 \mathrm{mg}$ & $1.72 \times 10^{-4}$ & 0.113 \\
$2 \mathrm{mg}$ & $2.54 \times 10^{-4}$ & 0.168 \\
$3 \mathrm{mg}$ & $4.24 \times 10^{-4}$ & 0.281 \\
$4 \mathrm{mg}$ & $4.97 \times 10^{-4}$ & 0.329 \\
$5 \mathrm{mg}$ & $5.94 \times 10^{-4}$ & 0.394 \\
$6 \mathrm{mg}$ & $5.06 \times 10^{-4}$ & 0.334 \\
\hline
\end{tabular}

The effect of the scans rates on the voltammetric response for the PtNPs/C/GCE was investigated in the same solution of $0.5 \mathrm{~mol} \mathrm{~L}^{-1} \mathrm{KCl}$ containing $0.01 \mathrm{~mol} \mathrm{~L}^{-1} \mathrm{~K}_{3}\left[\mathrm{Fe}(\mathrm{CN})_{6}\right]$, between -0.2 to $+0.6 \mathrm{~V} v s$. SCE. The recorded cyclic voltammograms (Supplementary material-SM2) exhibit a linear increase of the anodic peak current with square root of scan rate, which confirms that the electronic transfer process follows a diffusion-controlled mechanism [39], with no species being adsorbed on the PtNPs/C surface.

The selection of an appropriate substrate is an important initial step for many studies of electrochemically active materials. The material should exhibit favorable redox behavior for the analyte and reproducible electron transfer. As also determine the inertia potential window for material may be most suitable for application under different experimental conditions. The potential window of the PtNPS/C/GCE was evaluated in different $\mathrm{pH}$ solutions, from 1.0 to 10.0 (Supplementary material-SM3). The PtNPs/C/GC electrode demonstrated good electrochemical inertness in the $\mathrm{pH}$ range from 4.0 to 7.0 for an inertia potential window of $1.4 \mathrm{~V}(-0.6 \mathrm{~V}$ to $+0.8 \mathrm{~V}$ $v s$. SCE). The narrowest window was found in basic $(\mathrm{pH}>7)$ and acidic $(\mathrm{pH}<4)$ medium in which the electrode is limited in both anodic and cathodic ranges. The limitations can be related to the presence of functional groups in the carbon that can be oxidized or reduced.

The stability of PtNPs/C/GCE was investigated by recording successive $\mathrm{CV}$ between $-0.4 \mathrm{~V}$ to $+0.8 \mathrm{~V}$ vs. SCE at $25 \mathrm{mV} \mathrm{s}^{-1}$ in $0.1 \mathrm{~mol} \mathrm{~L}^{-1}$ phosphate buffer solution ( $\mathrm{pH}$ 3.0). The stable voltammetric profile with a slight increase with $5 \%$ of the capacitive current after 100 cycles indicated good PtNPs/C/GCE operational stability. 


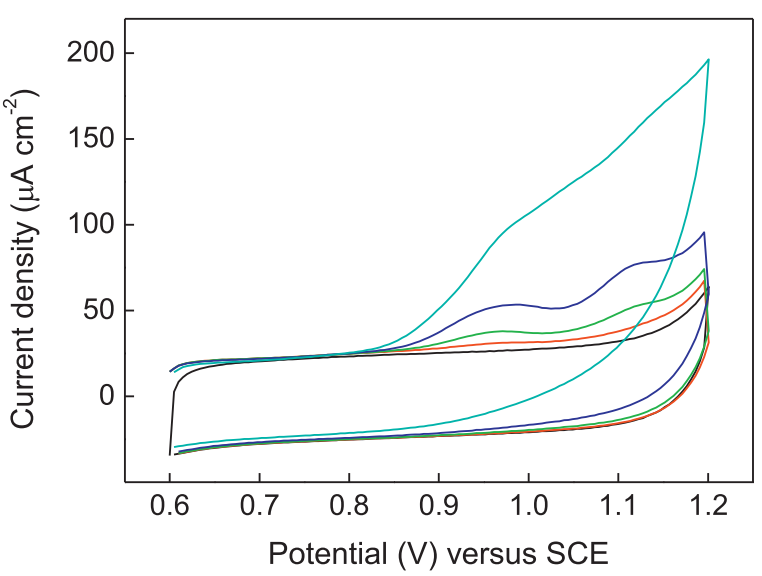

Fig. 4. Cyclic voltammograms recorded at the PtNPs/C/GC electrode in $0.1 \mathrm{~mol} \mathrm{~L}^{-1}$ phosphate buffer solution ( $\mathrm{pH}$ 3.0) in the absence (black curve) and presence of $1.01 \times 10^{-5} \mathrm{~mol} \mathrm{~L}^{-1}$ (red curve), $3.52 \times 10^{-5} \mathrm{~mol} \mathrm{~L}^{-1}$ (green curve), $1.83 \times 10^{-4} \mathrm{~mol} \mathrm{~L}^{-1}$ (blue curve) and $1.25 \times 10^{-3} \mathrm{~mol} \mathrm{~L}^{-1}$ of TTC (cyan curve). (For interpretation of the references to color in this figure legend, the reader is referred to the web version of this article.)

\subsection{Electrooxidation of tetracycline at the PtNPS/C/GCE}

In the present paper, the electrooxidation of TTC was investigated in $0.1 \mathrm{~mol} \mathrm{~L}^{-1}$ phosphate buffer ( $\mathrm{pH} 3.0$ ) by two different electrochemical techniques: cyclic voltammetry and differential pulse voltammetry. Cyclic voltammograms were obtained in the absence and presence of TTC, as shown in Fig. 4. The anodic peak current of the PtNPs/C/GC electrode increased significantly with the addition of TTC in buffer; in addition two other anodic processes near at $0.95 \mathrm{~V}$ and $1.15 \mathrm{~V} v$ s. SCE were observed. The presence of PtNP/C lead to a decrease in the overpotential of the first anodic peak with approximately $0.2 \mathrm{~V}$, compared to the bare GCE $[40,41]$, this decrease in the overpotential of TTC oxidation being greater compared with other electrochemical sensing platforms [24,40-43]. There was also a significant increase in peak currents at the PtNPs/C/GCe compared to the bare GCE, mostly due to an increase in the electroactive area. The oxidation peaks were clearly defined up to $1.25 \times 10^{-4} \mathrm{~mol} \mathrm{~L}^{-1}$ of TTC, for higher concentration being broader and difficult to be analyzed.

Furthermore, the electrochemical oxidation of TTC on PtNPs/C/GCE was studied by differential pulse voltammetry, with the aim to obtain a better definition of the oxidation peaks and to lower the detection limit of the sensor. Contrary to expectations, CV technique enabled detection of lower concentrations of TTC than DPV (see Fig. 5), the latter one detecting TTC for concentrations higher than $3.00 \times 10^{-4} \mathrm{~mol} \mathrm{~L}^{-1}, 100$ times higher than those enabled by CV. For this reason, CV was the electrochemical technique chosen to determine TTC in the following experiments.

The $\mathrm{pH}$ influence in the TTC electrooxidation on PtNPs/C was evaluated by cyclic voltammetry in $0.1 \mathrm{~mol} \mathrm{~L}^{-1}$ phosphate buffer solution, $\mathrm{pH} 1.0-7.0$, containing $6.02 \times 10^{-5} \mathrm{~mol} \mathrm{~L}^{-1} \mathrm{TTC}$. Analyzing the relation of anodic potential versus $\mathrm{pH}$ (Fig. 6) it was possible to observe a regular shift in the peak potential with buffer $\mathrm{pH}$, indicating the involvement of protons during TTC oxidation reaction. The first peak exhibited only one linear region (Eq. (2)), while the second peak, which is attributed to the oxidation of the product of first oxidation, showed two linear regions, one in the $\mathrm{pH}$ range from 2.0 to 4.0 (Eq. (3)) and other from 4.0 to 7.0 (Eq. (4)).

$$
E_{1 \text { st peak }}(\mathrm{V})=1.092-0.060 \mathrm{pH}(\mathrm{pH} 1.0 \text { to } 7.0) \quad(r=0.996 ; n=13)
$$

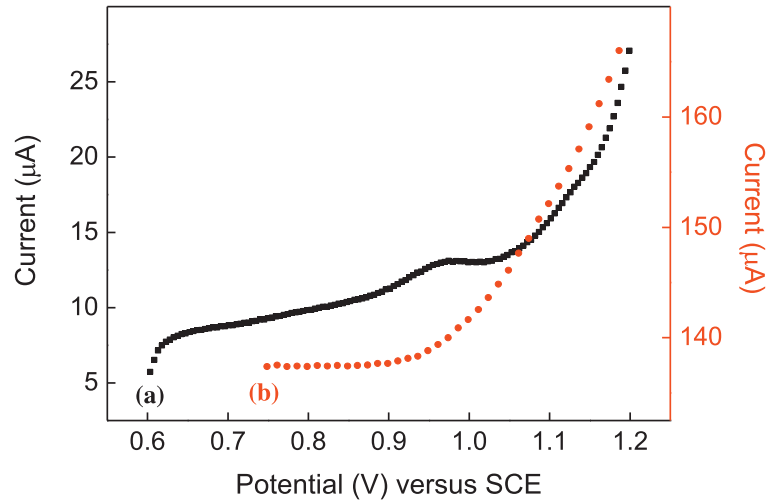

Fig. 5. Electrochemical response of the PtNPs/C/GC electrode in $0.1 \mathrm{~mol} \mathrm{~L}^{-1}$ phosphate buffer solution ( $\mathrm{pH}$ 3.0) in the presence of $2.27 \times 10^{-5} \mathrm{~mol} \mathrm{~L}^{-1}$ TTC using (a) cyclic voltammetry in a range potential from +0.6 to $+1.2 \mathrm{~V} v \mathrm{~s}$. SCE and $25 \mathrm{mV} \mathrm{s}^{-1}$ and (b) differential pulse voltammetry in range potential from 0.75 to $1.2 \mathrm{~V} v \mathrm{~s}$. SCE, amplitude pulse $50 \mathrm{mV}$ and $10 \mathrm{mV} \mathrm{s}^{-1}$. The cathodic line of $\mathrm{CV}$ was eliminated.

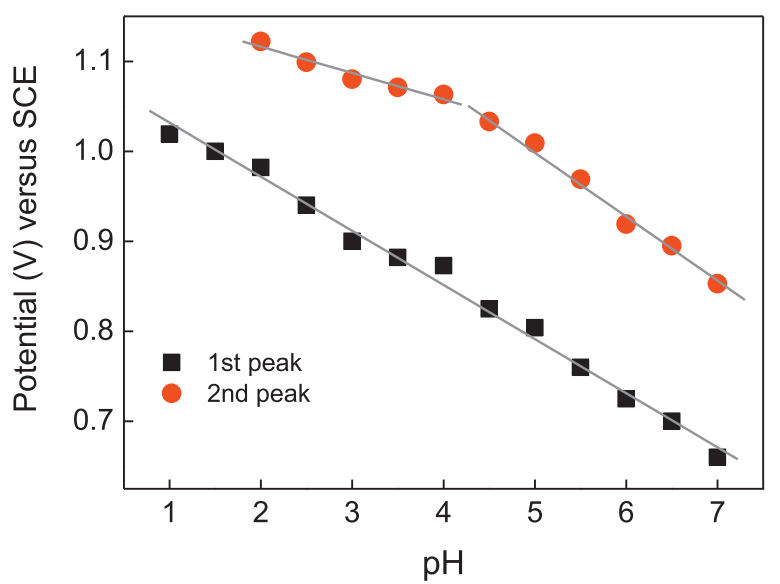

Fig. 6. pH influence on the anodic peak potential of TTC at the PtNPs/C/GCE.

$E_{\text {2nd peak }}(\mathrm{V})=1.175-0.029 \mathrm{pH}(\mathrm{pH} 2.0$ to 4.0$) \quad(r=0.973 ; n=4)$

$E_{2 \text { nd peak }}(\mathrm{V})=1.354-0.071 \mathrm{pH}(\mathrm{pH} 4.0$ to 7.0$)(r=0.996 ; n=7)$

From Eq. (2), the Nernstian slope of $60 \mathrm{mV} \mathrm{pH}^{-1}$ indicated the oxidation of TTC to occur by the involvement of the same number of electrons and protons [39]. The second anodic peak of the product of first oxidation showed slopes of $29 \mathrm{mV} \mathrm{pH}^{-1}(\mathrm{pH} \mathrm{2.0-4.0)}$ and $71 \mathrm{mV} \mathrm{pH}^{-1}$ ( $\mathrm{pH} 4.0-7.0$ ) that correspond to the mechanisms involved one proton and two electrons $\left(1 \mathrm{H}^{+} / 2 \mathrm{e}^{-}\right)$and same number of protons and electrons $\left(2 \mathrm{H}^{+} / 2 \mathrm{e}^{-}\right)$, respectively. The electrochemical behaviour of TTC oxidation products at the PtNPs/C/GCE can be explained in two steps:

(1st) the oxidation direct of the phenolic moiety with subsequent addition of the hydroxyl group [15,44-46], which can occur in two different positions, ortho and para (Scheme 1).

(2nd) the specific hydrogen interactions in the reduced quinone form could explain the difference in TTC oxidation for $\mathrm{pH}$ values below 4.0. After the electron/proton transfer to the para- or orthophenol moieties, strong intramolecular hydrogen interactions can take place [47] due to the high acidity of the environment. The 


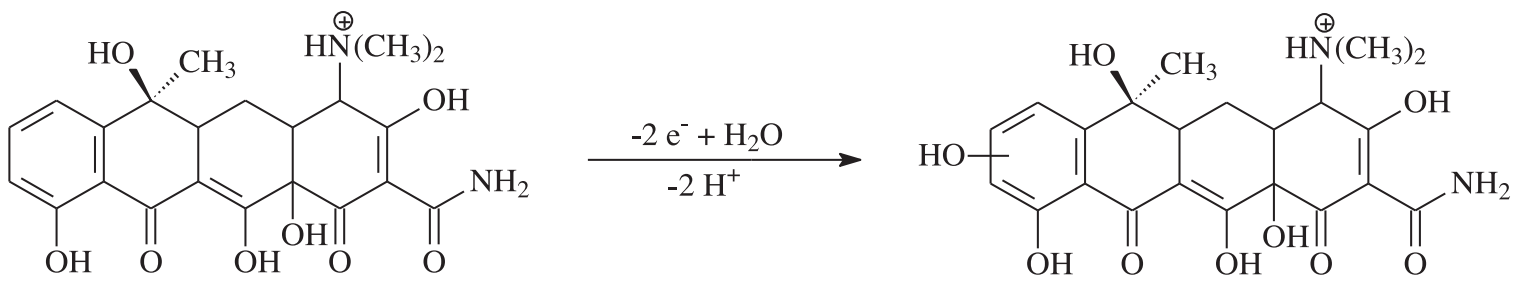

Scheme 1. Direct oxidation of TTC atthe PtNP/C/GCE with subsequent addition of the hydroxyl group.<smiles></smiles><smiles></smiles>

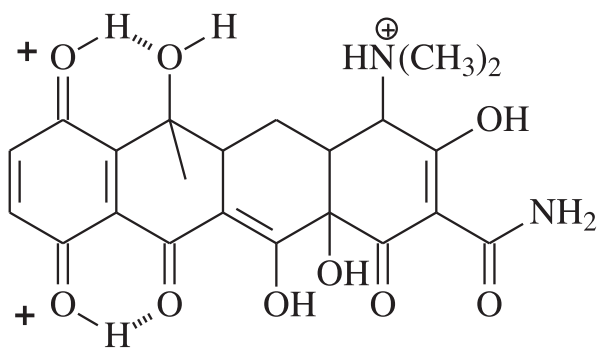<smiles></smiles><smiles>C[14CH3]</smiles><smiles>C[NH2+]C1C(O)=C(C(N)=O)C(=O)C2(O)C(O)=C3C(=O)C4=C5C(=O)C=CC(=O)[C@H]5[C@]4(C)C3CC12</smiles>

Scheme 2. The oxidation pathways of tetracycline.

sequence of the oxidation reaction is described as two rounds of electron-transfer coupled with the output of a proton (Scheme 2).

After investigation of the electrochemical oxidation of TTC at PtNPs/C/GCE, cyclic voltammetric measurements were carried out in a potential range from 0.6 to $1.2 \mathrm{~V} v \mathrm{~s}$. SCE in $0.1 \mathrm{~mol} \mathrm{~L}^{-1}$ buffer solution ( $\mathrm{pH}$ 3.0) containing different concentrations of TTC, from $9.99 \times 10^{-6} \mathrm{~mol} \mathrm{~L}^{-1}$ to $7.08 \times 10^{-5} \mathrm{~mol} \mathrm{~L}^{-1} \mathrm{TTC}$, in order to obtain an analytical curve (Fig. 7a).

The Fig. 7b shows the graph of the anodic current density dependence of the two oxidation peaks obtained by CV in function of the TTC concentration. Through this it is possible to observe two linear ranges for both oxidation peaks in accordance with the linear regression Eqs. (5) and (6). Considering the lowest linear range, the limit of quantification (ten times the blank signal/slope), the limit of detection (three times the blank signal/slope) [48] and sensitivity were determined, as presented in Table 2.

$j_{\text {pa }}\left(\mu \mathrm{A} \mathrm{cm}^{-1}\right)=26.6+3.33\left[\operatorname{TTC}\left(\mu \mathrm{mol} \mathrm{L}^{-1}\right)\right] 1$ st peak

Table 2

Analytical parameters obtained for the TTC determination at PtNPs/C/GCE.

\begin{tabular}{lll}
\hline & 1st peak $(\square)$ & 2nd peak $(\bullet)$ \\
\hline Linear range $\left(\mu \mathrm{mol} \mathrm{L}^{-1}\right)$ & $9.99-44.0$ & $9.99-44.0$ \\
Limit of quantification $\left(\mu \mathrm{mol} \mathrm{L}^{-1}\right)$ & 14.3 & 20.4 \\
Limit of detection $\left(\mu \mathrm{mol} \mathrm{L}^{-1}\right)$ & 4.28 & 6.12 \\
Sensitivity $\left(\mu \mathrm{AL} \mu \mathrm{mol}^{-1} \mathrm{~cm}^{-2}\right)$ & 3.32 & 4.06 \\
\hline
\end{tabular}

$j_{\mathrm{pa}}\left(\mu \mathrm{A} \mathrm{cm}^{-1}\right)=39.7+4.06\left[\mathrm{TTC}\left(\mu \mathrm{mol} \mathrm{L}^{-1}\right)\right] \quad 2$ nd peak

\subsection{Electroanalytical application in urine samples}

The tetracycline generally undergoes little or no metabolic transformations [49,50]. In this way, the enrichment of the urine with TCC standard should be near the actual analysis of the sample.

The analysis of the urine without the presence of TCC showed no electrochemical process, indicating the absence of possible interferences contained in the composition of human urine. However, when spiked urine sample was added in the electrochemical cell, two processes (at 0.92 and $1.09 \mathrm{~V} v$ s. SCE) were observed, attributed to TTC oxidation. With the multiple standard additions, these two electrochemical processes presented an increase of the anodic peak currents (Supplementary material-SM4). The TTC recovery results were obtained from the analysis of three different samples of spiked urine using the first oxidation peak, since this enabled lower limit of quantification and detection.

From these results, the PtNPs/C/GCE demonstrated to be efficient in the determination and quantification of low TTC concentrations in urine samples, with a maximum error in the recovery of $2.60 \%$ (Supplementary material). In this way, the results agreed at a confidence level of $95 \%$ according to student $t$-test, suggesting that the proposed method can be applied to analysis of real samples. 

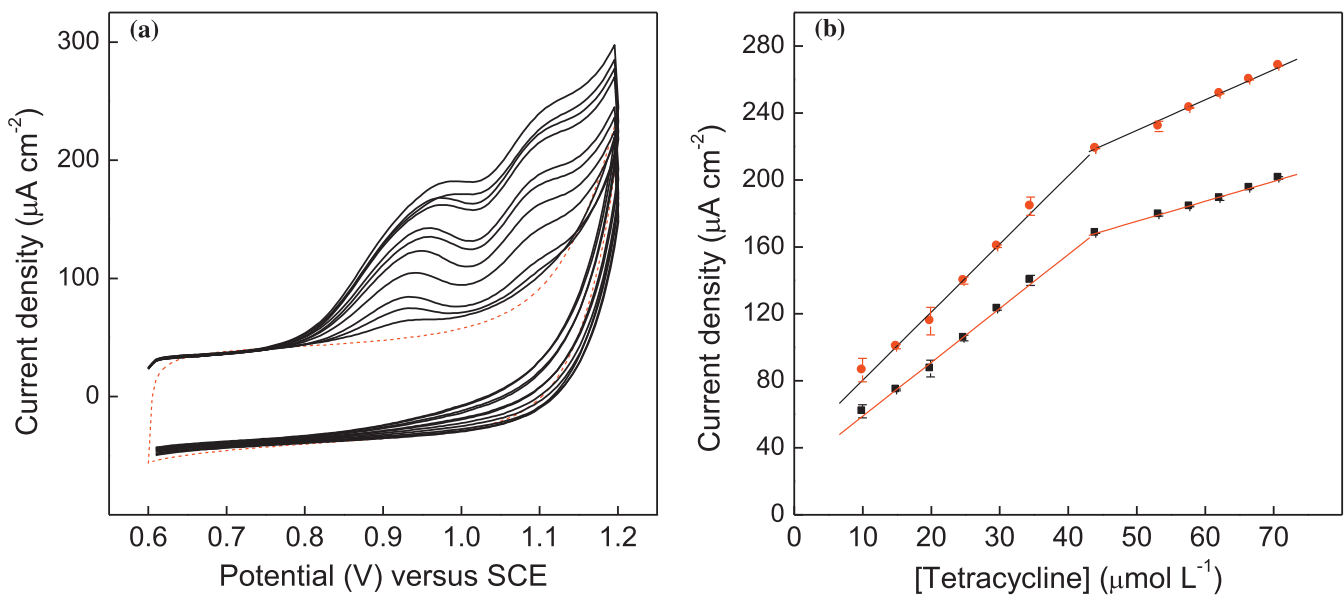

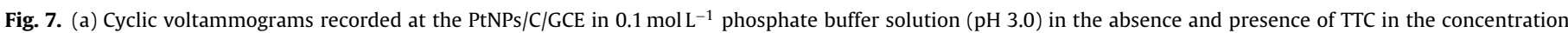

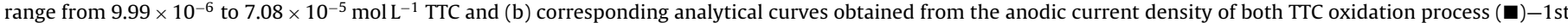
anodic peak and (0)-2nd anodic peak.

\section{Conclusion}

In this work, the platinum nanoparticles supported on carbon as electrochemical sensing platform in tetracycline determination was successful. The PtNPs/C showed good combination of activity and stability for tetracycline oxidation with favorable redox behavior for the analyte and reproducible electron transfer. The mechanism for the oxidation of TC was also proposed. Contrary to expectations, CV technique enabled detection of lower concentrations than DPV.

Recently, Guo et al. [25] developed an electrochemical aptasensor for tetracycline using gold nanoparticles, methylene blue and anti-tetracycline aptamer on the glassy carbon electrode. Under optimum conditions, this aptasensor showed an analytical performance for tetracycline detection with a detection limit of $0.42 \times 10^{-11} \mathrm{~mol} \mathrm{~L}^{-1}$. By comparison, our proposal is simple, lower cost, and fast analysis of the antibiotic.

\section{Acknowledgments}

The authors are grateful for the financial supports provided by FAPESP (2005/01296-4) and CNPq (302728/2012-0). The scholarship granted by CAPES to R.T. Kushikawa is gratefully acknowledged. We also thank to Madalina Barsan by English revision. .

\section{Appendix A. Supplementary data}

Supplementary data associated with this article can be found, in the online version, at http://dx.doi.org/10.1016/j.snb.2016.01.009.

\section{References}

[1] K. Kumar, S.C. Gupta, Y. Chander, A.K. Singh, Antibiotic use in agriculture and its impact on the terrestrial environment, Adv. Agron. 87 (2005) 1-54

[2] E.C. Pereira-Maia, P.P. Silva, W.B. de Almeida, H.F. dos Santos, B.L. Marcial, R. Ruggiero, W. Guerra, Tetracyclines and glycylcyclines: an overview, Quim. Nova 33 (2010) 700-706.

[3] P. Wang, Y.L. He, C.H. Huang, Reactions of tetracycline antibiotics with chlorine dioxide and free chlorine, Water Res. 45 (2011) 1838-1846.

[4] B. Suadrez, B. Santos, B.M. Simonet, S. Cardenas, M. Valcarcel, Solid-phase extraction-capillary electrophoresis-mass spectrometry for the determination of tetracyclines residues in surface water by using carbon nanotubes as sorbent material, J. Chromatogr. A 1175 (2007) 127-132.

[5] B.Y. Deng, O.X. Xu, H. Lu, L. Ye, Y.Z. Wang, Pharmacokinetics and residues of tetracycline in crucian carp muscle using capillary electrophoresis on-line coupled with electrochemiluminescence detection, Food Chem. 134 (2012) 2350-2354.
[6] I.S. Ibarra, J.A. Rodriguez, J.M. Miranda, M. Vega, E. Barrado, Magnetic solid phase extraction based on phenyl silica adsorbent for the determination of tetracyclines in milk samples by capillary electrophoresis, J. Chromatogr. A 1218 (2011) 2196-2202.

[7] C. Nebot, M. Guarddon, F. Seco, A. Iglesias, J.M. Miranda, C.M. Franco, A. Cepeda, Monitoring the presence of residues of tetracyclines in baby food samples by HPLC-MS/MS, Food Control 46 (2014) 495-501.

[8] X.Q. Yang, C.X. Yang, X.P. Yan, Zeolite imidazolate framework-8 as sorbent for on-line solid-phase extraction coupled with high-performance liquid chromatography for the determination of tetracyclines in water and milk samples, J. Chromatogr. A 1304 (2013) 28-33.

[9] A. Tolgyesi, L. Tolgyesi, K. Bekesi, V.K. Sharma, J. Fekete, Determination of tetracyclines in pig and other meat samples using liquid chromatography coupled with diode array and tandem mass spectrometric detectors, Meat Sci. 96 (2014) 1332-1339.

[10] Q. Zhou, Y.Y. Zhang, N. Wang, L.H. Zhu, H.Q. Tang, Analysis of tetracyclines in chicken tissues and dung using LC-MS coupled with ultrasound-assisted enzymatic hydrolysis, Food Control 46 (2014) 324-331.

[11] S. Sivakesava, J. Irudayaraj, Rapid determination of tetracycline in milk by FT-MIR and FT-NIR spectroscopy, J. Dairy Sci. 85 (2002) 487-493.

[12] J.B. Ghasemi, A.R. Jalalvand, Multi-wavelength spectrophotometric determination of the protolytic constants of tetracycline hydrochloride in some nonaqueous-water mixed solvents: a solvatochromism study, Spectrochim. Acta A 78 (2011) 277-286.

[13] C.L. Kuong, T.J. Yu, Y.C. Chen, Microwave-assisted sensing of tetracycline using europium-sensitized luminescence fibers as probes, Anal. Bioanal. Chem. 395 (2009) 1433-1439.

[14] L.S. Liu, G.Y. Chen, M.L. Fishman, A single sorbent for tetracycline enrichment and subsequent solid-matrix time-resolved luminescence, Anal. Chim. Acta 528 (2005) 261-268.

[15] X.P. Dang, C.G. Hu, Y.L. Wei, W.H. Chen, S.S. Hu, Sensitivity improvement of the oxidation of tetracycline at acetylene black electrode in the presence of sodium dodecyl sulfate, Electroanalysis 16 (2004) 1949-1955.

[16] C.M.F. Calixto, E.T.G. Cavalheiro, Determination of tetracyclines in bovine and human urine using a graphite-polyurethane composite electrode, Anal. Lett. 48 (2015) 1454-1464

[17] C.M.F. Calixto, P. Cervini, E.T.G. Cavalheiro, Determination of tetracycline in environmental water samples at a graphite-polyurethane composite electrode, J. Braz. Chem. Soc. 23 (2012) 938-943.

[18] M.D. Glinchuk, V.V. Khist, E.A. Eliseev, A.N. Morozovska, Oxide nanomaterials with properties absent in bulk (author review), Powder Metall. Metal C+ 52 (2013) 32-38

[19] M.A. El-Sayed, Some interesting properties of metals confined in time and nanometer space of different shapes, Acc. Chem. Res. 34 (2001) 257-264.

[20] V. Biju, T. Itoh, A. Anas, A. Sujith, M. Ishikawa, Semiconductor quantum dots and metal nanoparticles: syntheses, optical properties, and biological applications, Anal. Bioanal. Chem. 391 (2008) 2469-2495.

[21] C.M. Welch, R.G. Compton, The use of nanoparticles in electroanalysis: a review, Anal. Bioanal. Chem. 384 (2006) 601-619.

[22] F.W. Campbell, R.G. Compton, The use of nanoparticles in electroanalysis: an updated review, Anal. Bioanal. Chem. 396 (2010) 241-259.

[23] R.M.A. Hameed, Amperometric glucose sensor based on nickel nanoparticles/carbon Vulcan XC-72R, Biosens. Bioelectron. 47 (2013) $248-257$.

[24] H.T. Wang, H.M. Zhao, X. Quan, S. Chen, Electrochemical determination of tetracycline using molecularly imprinted polymer modified carbon nanotube-gold nanoparticles electrode, Electroanalysis 23 (2011) 1863-1869. 
[25] Y.M. Guo, X.Y. Wang, X. Sun, A label-free electrochemical aptasensor based on electrodeposited gold nanoparticles and methylene blue for tetracycline detection, Int. J. Electrochem. Sci. 10 (2015) 3668-3679.

[26] S. Faridah, R. Hazana, A.R. Gayah, Z. Norzaili, A. Azima, M.S. Nur Azura, I. Zamri, Electrochemical sensors for detection of tetracycline antibiotics, Malays. J. Anim. Sci. 15 (2012) 67-80.

[27] M. Asadollahi-Baboli, A. Mani-Varnosfaderani, Rapid and simultaneous determination of tetracycline and cefixime antibiotics by mean of gold nanoparticles-screen printed gold electrode and chemometrics tools, Measurement 47 (2014) 145-149.

[28] M.R. da Silva, A.C.D. Angelo, Synthesis and characterization of ordered intermetallic nanostructured $\mathrm{PtSn} / \mathrm{C}$ and $\mathrm{PtSb} / \mathrm{C}$ and evaluation as electrodes for alcohol oxidation, Electrocatalysis 1 (2010) 95-103.

[29] C. Roychowdhury, F. Matsumoto, P.F. Mutolo, H.D. Abruna, F.J. DiSalvo, Synthesis, characterization, and electrocatalytic activity of PtBi nanoparticles prepared by the polyol process, Chem. Mater. 17 (2005) 5871-5876.

[30] L.R. Alden, D.K. Han, F. Matsumoto, H.D. Abruna, F.J. DiSalvo, Intermetallic $\mathrm{PtPb}$ nanoparticles prepared by sodium naphthalide reduction of metal-organic precursors: electrocatalytic oxidation of formic acid, Chem. Mater. 18 (2006) 5591-5596.

[31] H.E. Zittel, F.J. Miller, A glassy-carbon electrode for voltammetry, Anal. Chem. 37 (1965) 200.

[32] E.T.G. Cavalheiro, C.M.A. Brett, A.M.O. Brett, O. Fatibello, Bioelectroanalysis of pharmaceutical compounds, Bioanal. Rev. 4 (2012) 31-53.

[33] N. Laube, B. Mohr, A. Hesse, Laser-probe-based investigation of the evolution of particle size distributions of calcium oxalate particles formed in artificial urines, J. Cryst. Growth 233 (2001) 367-374.

[34] C.M.A. Brett, A.M.O. Brett, Electrochemistry: Principles, Methods, and Applications, Oxford University Press, Oxford, 1993.

[35] C.G. Zoski, Handbook of Electrochemistry, 1st ed., Elsevier, Amsterdam, Boston, 2007

[36] M. Vonstackelberg. M. Pilgram, V. Toome, Bestimmung Von Diffusionskoeffizienten Einiger Ionen in Wassriger Losung in Gegenwart Von Fremdelektrolyten, Z. Elektrochem. 57 (1953) 342-350.

[37] F.G. Will, Bromine diffusion through nafion perfluorinated ion-exchange membranes, J. Electrochem. Soc. 126 (1979) 36-43.

[38] S.H. Chen, R. Yuan, Y.Q. Chai, L.G. Min, W.J. Li, Y. Xu, Electrochemical sensing platform based on tris(2,2'-bipyridyl) cobalt(III) and multiwall carbon nanotubes-nafion composite for immunoassay of carcinoma antigen-125. Electrochim. Acta 54 (2009) 7242-7247.

[39] A.J. Bard, L.R. Faulkner, Electrochemical Methods: Fundamentals and Applications, 2nd ed., Wiley, New York, 2001.

[40] S. Treetepvijit, A. Preechaworapun, N. Praphairaksit, U. Chuanuwatanakul, Y. Einaga, O. Chailapakul, Use of nickel implanted boron-doped diamond thin film electrode coupled to HPLC system for the determination of tetracyclines, Talanta 68 (2006) 1329-1335

[41] T. Gan, Z.X. Shi, J.Y. Sun, Y.M. Liu, Simple and novel electrochemical sensor for the determination of tetracycline based on iron/zinc cations-exchanged montmorillonite catalyst, Talanta 121 (2014) 187-193.

[42] H.T. Wang, H.M. Zhao, X. Quan, Gold modified microelectrode for direct tetracycline detection, Front. Environ. Sci. Eng. 6 (2012) 313-319.
[43] N. Wangfuengkanagul, W. Siangproh, O. Chailapakul, A flow injection method for the analysis of tetracycline antibiotics in pharmaceutical formulations using electrochemical detection at anodized boron-doped diamond thin film electrode, Talanta 64 (2004) 1183-1188.

[44] J. Jeong, W.H. Song, W.J. Cooper, J. Jung, J. Greaves, Degradation of tetracycline antibiotics: mechanisms and kinetic studies for advanced oxidation/reduction processes, Chemosphere 78 (2010) 533-540.

[45] D.A. Borisova, M.D. Vedenyapina, I.V. Krylova, A.K. Rakishev, D. Weichgrebe, P. Stopp, K.H. Rosenwinkel, A.A. Vedenyapin, Electrochemical oxidation of tetracycline on a boron doped diamond electrode within the stability potentials of water, Russ. Chem. B+ 62 (2013) 2590-2594

[46] P.Y. Bruice, Organic Chemistry, 6th ed., Prentice Hall, Upper Saddle River, NJ 2010.

[47] C.S. Martin, M.F.S. Teixeira, Electrocatalytic study of an electrode modified with Reactive Blue 4 dye covalently immobilized on amine-functionalized silica, J. Solid State Electrochem. 16 (2012) 3877-3886.

[48] J. Mocak, A.M. Bond, S. Mitchell, G. Scollary, A statistical overview of standard (IUPAC and ACS) and new procedures for determining the limits of detection and quantification: application to voltammetric and stripping techniques (technical report), Pure Appl. Chem. 69 (1997) 297-328.

[49] M. Hoffmann, W. DeMaio, R.A. Jordan, R. Talaat, D. Harper, J. Speth, J.A Scatina, Metabolism, excretion, and pharmacokinetics of [C-14] tigecycline, a first-in-class glycylcycline antibiotic, after intravenous infusion to healthy male subjects, Drug Metab. Dispos. 35 (2007) 1543-1553.

[50] K.N. Agwuh, A. MacGowan, Pharmacokinetics and pharmacodynamics of the tetracyclines including glycylcyclines, J. Antimicrob. Chemother. 58 (2006) 256-265.

\section{Biographies}

Ricardo Tomitan Kushikawa is graduate in chemistry from São Paulo State University and science master in the area of analytical chemistry by University of São Paulo (USP).

Marcelo R. Silva Marcelo Rodrigues da Silva obtained his PhD degree (Material Science) in 2012 at the São Paulo State University (UNESP). Currently, he is Professor at the Colégio Técnico Industrial "Prof. Isaac Portal Roldán". His research interests are in the electrochemistry and material science.

Antonio Carlos Dias obtained his Ph.D. degree (Physical Chemistry) in 1993 at the Universidade de São Paulo. Currently, he is an Adjunct Professor at the Department of Chemistry of the São Paulo State University (UNESP)-Campus Bauru. His research interests are in the electrochemistry and materials science with emphasis in fuel cell.

Marcos Fernando de Souza Teixeira obtained his Ph.D. degree (Analytical Chemistry) in 2000 at the Universidade de Federal de São Carlos. Currently, he is an Associate Professor at the Department of Chemistry and Biochemistry of the São Paulo State University (UNESP)-Campus Presidente Prudente. His research interests are in the development of chemical sensing concepts, electrochemical sensors based on polymeric sensing phases and environmental electroanalytical. 